\title{
Editorial
}

\section{Muscle: The eternally ecofriendly automobile}

\author{
Manu Kothari, Atul Goel ${ }^{1}$ \\ Departments of Anatomy and ${ }^{1}$ Neurosurgery, King Edward Memorial Hospital \& Seth G.S. Medical College, Parel, Mumbai, India
}

It was about 4.2 billion years ago that there was a lifebang that spawned the first cell - the protocyte - that began the story of life that continues till to-date. A part of the cytoverse is myosin-actin complex that endows power to move things within, and to propel itself in relation to the milieu. Thus came into being the first ever automobile that can move sans any pull or push. Evolutionary water flowed and begot larger, metazoans that asked the versatile zygote to beget mesoderm a part of which formed the microscopically recognizable muscle cells.

Muscle is an adaptation from $L$ musculus, meaning a little mouse as a child's contracted biceps brachii would look like, or the rippling under the skin that one would feel when some muscles are in action. It is significant that whereas it is the biomouse (muscle) that makes a midget or a mammoth move, it is the technomouse under your palm that moves information within a computer and across the ocean and to Jupiter and back. The biomouse is ecofriendly, the technomouse and its backup an acknowledged E-tech environmental disaster. Nonmuscle- power, namely fossil-fuel and electricity are hardly 200 years old. Muscle-power - animal and human - has spawned the greatest civilizations, boasting of Pyramids and Parthenon, Scandinavia has realized the perils of man-made power, and are reviving animal-farming. John Steinback, in The Grapes of Wrath, laments that the tractor deadened the neighing and hoof-beats of the horse that animated (anima - atma) one's house even when the animal was not at work. The BBC recently sought the opinion of over 12000 people spread the world-over as to the greatest invention of the last 200 years, and a whopping 67\% gave the humanpropelled BICYCLE the pride of place, as universally useful, ecofriendly and homofriendly. Hail, the miracle called MUSCE CELL. By 2060, all oil reserves are expected to be over, and the humble bicycle will make a global come-back, freeing you of the need to take any statin, or resort to a plasty or bypass.

Guy Murchie describes human body as a 'corporation of 100 organs, 200 bones, 600 muscles, trillions of cells, and octillions of atoms that are physically you, a human cosmopolis, a mysterious going concern'. The 600 muscles account for the entire human civilization, the Vedic and Voltairean manuscripts, many a men-made wonder, the grace of Birjoo Maharaj or Isadora Duncan, the verse-ability of Lata Mangeshkar, and the strokes of M.F. Hussain, not to miss out on Michael Angelo's Pieta on the one hand, and the unnamed sculptors of the Taj Mahal on the other. Muscle makes miracles. To this set of wonders, add the 3 billion + heart-beats and 1 billion + chestbeats you are empowered with over a span of 100 years, not to talk of a million miles traveled on the GI and GU tracts.

Claudius Galen (131-201 AD) can be held as the pioneer myologist that described over 300 muscles and gave such lasting names as platysma, cremaster, masseter, popliteus, and interossei. Then the Titanic Vesalius in 1543 botched up the issue by giving numbers in place of names, confusion worse confounded cleared by his contemporary Sylvius who once and for ever rendered muscle-naming an art - peroneus, tibialis, scaleni, rhomboidei, serrati, soleus and a lot more came from him, supplemented over the years by Riolan, Winslow, Albinus, Cowper, Douglas and others.

The phylogeny and ontogeny of muscles make an interesting reading. The outermost cells of the embryonic cylinder are ectocytes comprising the ectoderm, that facing the milieu exterior, have to fashion the sensory receptors (Sensorium), neurons (Neuronium), and musculature (Motorium), the cells comprising which HAVE to be linked point-to-point as if on a printed electronic circuit, once and forever, a prime reason that endows these cells the status of postmitosis, immortality, or perenniality. These are terms coined not by any spiritualist, but by Leblond who pioneered classification of cells into Perennial, Expanding, and Renewing, in the 1960's. The world-to-us is because of our sensorium, the world-within-us is the function of our neuronium, and the world-because-of-us is the genius 
of our motorium or muscles. Every man-made menace or miracle is traceable to musculus, little mouse, called a muscle cell. The inherent unity between a sensory receptor, neurone and muscle cell is best illustrated by the embryonic myocardial cells that fashion the might of the heart, make its pacemakers, as also the sensory receptors that mediate all the reflexes.

Human embryogenesis is complete by 8 weeks of intrauterine life, when not a spicule of bone is around, and each of the $600+$ muscles are fully fashioned. Human embryogenesis is then an unosseous (wrongly called invertebrate) affair. Bones arrive as an afterthought, and it is they that seek 'attachment' to the preformed muscles. The bones DO NOT provide strength to the muscles but only serve to form a set of levers to deflect/direct/coordinate muscle power, or to give a spread to them like scapula and pelvis do. The three great boneless wonders that are full of might are the parturient uterus (rated by Gray as more powerful than the gluteus maximus), the heart, and the elephant's trunk. The loligo, the largest invertebrate measuring 50-80 feet, is the fastest swimmer in the ocean, capable of covering 42 Knots an hour, and outpacing the sharks and the whales, for it is the only animal that swims by jet-propulsion, offered to it by its 'visceral' muscles. The human pharynx and much of esophagus have striated musculature that is involuntary. Striation, then, in the heart or the soma, provides speed, and non-striation sustained gentle action. In fact, none of the so-called skeletal muscles is voluntary. As Gray's Anatomy elaborates, the brain knows movements, and not muscles. In any movement minor or major, precise or gross, a definite set of muscles go into action. No single muscle can be added by will, nor one deducted. The appellations voluntary/involuntary have no merit.

The now widely accepted Homoeobox (HOX) theory generalizes that Nature follows the same embryogenic/ somatic model be it the smallest worm or the largest whale, wherein the muscular arrangement and working remain essentially the same, accounting thereby for 'swimming muscles of a whale that pitches five times a minute to the flight muscles of a midge that beats its wings a thousand times a second'. The aggregate muscles power of an average human can lift a weight of 25 tons. The extreme of animal power has been recorded of a whale harpooned from a heavy whaler, dragging the same for miles into the sea, despite full throttle of the $550 \mathrm{HP}$ ship in the contrary direction.

Despite the Nobel award to Huxley and Hodgkin for their theory of muscle contraction, we are still in the dark as to how we wag our little finger. A skeletal muscle is provided with sensory-musculature that we call the muscle-spindle. So any so-called motor movement demands cosmic sensory integration. It would seem that for the smallest action, 'willed' or otherwise, the entire sensory-neurono-motor complex goes into action, thus abolishing the distinctions we perceive between Sensorium, Neuronium and Motorium. So many a disorder, be it chorea or Parkinsonism, is no isolated disorder, but a concerted one. The degenerative myopathies are an antithesis to the perennial nature of muscle cells. However since most of us sail through life, without being much handicapped, we can, with due reverence and humility, generalize that all myopathies have a message that some future Nobel Laureates will decode towards our better appreciation of the little mice we all carry within ourselves.

From 1898, the first Olympics, to the recently concluded at Beijing, there has not been a single one when no records were shattered. Bolt's record sprint in 100/200 meters not only speaks of the superior musculature of a race, but also of the ever-obedient marvel called human musculature. And we have just learnt that Haile Gebrelassie of Ethopia finished the Berlin Marathon in 123 minutes, i.e. less than 5 minutes a mile, sustained for 26 miles. The immortality that men attain through their works is engineered by the immortal muscle cells within their mortal frame.

MUSCLE as a pregnym, can mean Motor Unit Serving Circulation, Labor and Elegance. The Circulatory component subserves all the body flows and intrinsic movements whereas Labor and Elegance are manifest locomotor system. 